\title{
Genetic Influences on Peer and Family Relationships Across Adolescent Development: Introduction to the Special Issue
}

\author{
Paula Y. Mullineaux ${ }^{1} \cdot$ Lisabeth Fisher DiLalla $^{2}$
}

Received: 6 May 2015/Accepted: 16 May 2015/Published online: 26 May 2015

(C) Springer Science+Business Media New York 2015

\begin{abstract}
Nearly all aspects of human development are influenced by genetic and environmental factors, which conjointly shape development through several gene-environment interplay mechanisms. More recently, researchers have begun to examine the influence of genetic factors on peer and family relationships across the pre-adolescent and adolescent time periods. This article introduces the special issue by providing a critical overview of behavior genetic methodology and existing research demonstrating geneenvironment processes operating on the link between peer and family relationships and adolescent adjustment. The overview is followed by a summary of new research studies, which use genetically informed samples to examine how peer and family environment work together with genetic factors to influence behavioral outcomes across adolescence. The studies in this special issue provide further evidence of gene-environment interplay through innovative behavior genetic methodological approaches across international samples. Results from the quantitative models indicate environmental moderation of genetic risk for coercive adolescent-parent relationships and deviant peer affiliation. The molecular genetics studies provide support for a gene-environment interaction differential susceptibility model for dopamine regulation genes across positive and negative peer and family environments. Overall, the findings from the studies in this special issue
\end{abstract}

Lisabeth Fisher DiLalla

ldilalla@siu.edu

1 Department of Psychology, MS-B1805, Hamline University, 1536 Hewitt Ave., St. Paul, MN 55104, USA

2 Family and Community Medicine, Mail Code 6503, Southern Illinois University School of Medicine, Carbondale, IL 62901, USA demonstrate the importance of considering how genes and environments work in concert to shape developmental outcomes during adolescence.

Keywords Behavior genetics $\cdot$ Peers $\cdot$ Parenting $\cdot$ Twins · Gene-environment interaction

\section{Introduction}

Child and adolescent development have been examined traditionally from an environment-focused behavioral perspective. This perspective has provided important information about the role of the social environment on youth development. However, with today's wide consensus that almost all aspects of human development are influenced by both genetic and environmental factors, there is a growing interest in understanding how genetic and environmental effects influence developmental trajectories of children and adolescents (Turkheimer 2000).

Numerous investigations across a variety of developmental domains have implicated significant genetic and environmental influences. For example, twin studies have indicated increasing heritability, or genetic influences, on cognitive ability across childhood through adolescence and into adulthood (McCartney et al. 1990; McGue et al. 1993; Plomin 1986; for a recent review see Tucker-Drob et al. 2013). In a recent twin study, the heritability of cognitive ability was shown to increase from $41 \%$ in middle childhood to $55 \%$ in preadolescence and to $66 \%$ by late adolescence (Haworth et al. 2010). These results indicate that the influences of genes and environmental effects on cognitive ability change across the transition from childhood to adolescence in a dynamic rather than static fashion. 
Another developmental domain frequently examined from a behavioral genetic perspective is temperament. Although heritability differs from sample to sample, genes generally account for 20-60\% of the variance in temperament within a population (Saudino 2005). This indicates the presence of moderate to strong genetic influences on temperament variability. The heritability estimates of temperament also follow a similar pattern as that observed for cognitive ability, with the influence of genetic factors increasing from infancy through childhood (Rettew and McKee 2005). From a developmental perspective, these findings are intriguing as they may provide a clearer understanding of the mechanisms involved in developmental differences observed across the transition from early childhood through adolescence. This literature indicates the importance of both genetic and environmental influences in explaining differences in developmental outcomes.

Behavioral genetic research has clearly established the importance of considering both genetic and environmental factors across an array of developmental domains for a more complete understanding of developmental variability. However, it is only recently that we have begun to elucidate the role of gene-environment interplay in explaining developmental variability. The initial conceptualizations of genetic and environmental effects posited that each type of effect operated in an independent fashion, with any interaction between the two factors serving as the exception rather than the rule (Wachs 1983). This view of limited interplay between genetic and environmental factors did not persist, and for several decades now the predominant thought has been that the interrelations between genes and environments are more likely the rule rather than the exception. This view is supported by the extensive literature indicating gene-environment interplay across a variety of psychological domains. Over the $21^{\text {st }}$ century, a growing body of empirical evidence supports the view that genetic and environmental factors work conjointly rather than independently on children's and adolescents' developmental outcomes, through various mechanisms of gene-environment interplay.

Although there is clear support for gene-environment interplay, the majority of work examining development across childhood and adolescence has focused on the role of the social environment to explain differences in the developmental outcomes of youth. This extant literature has indicated that family-related factors, such as parenting style (Bank et al. 2004; Williams et al. 2009), parent-child relationship quality (Bank et al. 2004; Gass et al. 2007; Kaczynski et al. 2006), and aspects of the sibling-relationship (Bank et al. 2004; Richmond et al. 2005; Tucker and Updegraff 2009; Williams et al. 2007), are significantly associated with psychosocial adjustment during this developmental period. However, most of these studies do not account for potential genetic influences on children's behavior and ultimate developmental outcomes during this period, thus providing an incomplete picture of potential underlying developmental mechanisms. More recent quantitative behavioral genetic investigations have begun to examine how these family-related environmental and genetic factors work together in explaining differences in developmental outcomes (e.g., Bakermans-Kranenburg and van IJzendoorn 2007; Kim-Cohen et al. 2006; Thapar et al. 2007).

Researchers interested in the role of the social environment on youth adjustment also have looked beyond the family environment to the peer environment. Children's exposure to peer environments begins well before adolescence as children in most contemporary societies spend a large portion of their day in the company of same-age peers in childcare and school settings. The opportunity for early peer environment influences on children's development has the potential to begin at an early age, leading to peer experiences that clearly take center stage during adolescence (Bukowski et al. 2006). Peer environments and peer relationships provide an important developmental context for the learning of new social skills, social roles and norms, and development of self-concept (Boivin et al. 2005). Additionally, healthy peer relationships may protect youth from maladjustment (i.e., internalizing or externalizing problem behaviors) (Boivin et al. 2005; Bukowski et al. 2006). However, our understanding of how genes and environments work together to explain the link between peer relationships and youth psychosocial adjustment is somewhat limited. Newer studies are beginning to make headway in understanding this gene-environment link, and many of these studies use adolescent populations. This special issue is designed to provide some of the evidence for the importance of considering genes and their relations with the environment in forming more complete models of adolescent development.

To lay the groundwork for the articles in this special issue, we provide a brief explanation of the basic principles in behavior genetics research, as well as brief descriptions of the ways in which genes and environment may correlate or interact. We then provide a summary of some of the many findings from the behavior genetics literature that are relevant for this special issue on parent and peer relationships in adolescence.

\section{Behavior Genetics: A Brief Primer}

The field of human behavioral genetics relies on several types of studies that are designed to examine both genetic and environmental influences on human behavior. Two quasi-experimental approaches, the twin design and the 
adoptee design, use samples that occur naturally and that provide opportunities to tease apart genetic and environmental influences (DiLalla et al. 2012). Other types of studies that use similar methods include the use of twins reared apart, families of twins, and siblings with differing degrees of genetic relatedness. In addition, since the advent of affordable genotyping, molecular genetics designs allow us to examine specific genotypes and analyze their relatedness to various human behaviors. Each of these methods has advantages and disadvantages. Ideally, researchers will make use of different methodologies to demonstrate similar findings, which would provide stronger evidence for the conclusions.

To understand the concepts of the influences of genes and environment on behavior, we first present a discussion of heritability and the types of environment that are considered in behavioral genetic work. Then methods particular to this special issue will be described. In this special issue, articles use twin designs as well as molecular genetic data, and therefore these two methods are discussed below, with both pros and cons presented. We then discuss how genes and environment work together to influence behaviors.

\section{Heritability and Environment}

Heritability is a statistic that is estimated based on measures of similarity between groups of people who share genes to various degrees. It represents the amount of phenotypic variance (variance of the behavior that is measured) that can be attributed to genetic factors. It is essential to understand (and this often is misunderstood) that heritability is simply a statistic, and as such is subject to the rules of statistics. The most important is that an estimate of heritability is particular to the sample that was studied. Questions of generalizability apply to this statistic just as they apply to all studies. Thus, it is inaccurate to measure heritability in one sample and then to deduce that two samples that differ on a particular measure must therefore be genetically different. For example, intelligence has been shown to be heritable. However, the finding that people from different socioeconomic (SES) backgrounds differ on intelligence scores does not mean that one group is genetically "smarter" than the other group (DiLalla and DiLalla 1995). In fact, when these two groups are assessed for heritability of intelligence, we see that those from very low SES environments have blunted heritability estimates because the environment is so stunting that it does not allow genetic ability to be expressed, and this has been shown in very early childhood (Tucker-Drob et al. 2011) through later childhood (Turkheimer et al. 2003). Thus, it is terribly important to assess heritability of various behaviors across environments and cultures to have a better understanding of the role that genes play in affecting behaviors. This special issue includes studies from several different cultures that provide important contributions to our understanding of the generalizability of genetic influences.

The two types of broad genetic influences on behavior are additive and dominant influences. Variance in a behavior is accounted for by additive genetic influence if the effect of the genes is additive in nature, meaning that the more genes one has that are related to the outcome measure, the more the behavior is exhibited. Dominant genetic influences are evidenced by an interaction in genes affecting the behavior under study. This can happen in a number of ways. For instance, one gene can mask the effects of another. Another example is that having one copy of one gene or one copy of a second gene might increase the likelihood of a behavior being exhibited, but having both genes might triple or quadruple the likelihood of the behavior being shown. Both additive and dominant genetic effects are evidence of genes influencing behavior; they simply are different mechanisms for this influence.

Behavior genetic designs also partition environmental variance into two types of environment, shared and nonshared. Shared environment, by definition, includes environmental influences that are shared between members of a family. For instance, when parents divorce, this environment is shared by the children. However, the children will experience this in different ways, depending on their different ages when the divorce occurs, their different personalities, and other experiences they may have had that they do not share. Thus, divorce also will have a nonshared environmental impact on the children. Nonshared environment includes environmental influences that are not shared by members of the family, and this includes measurement error, which should be idiosyncratic and therefore nonshared.

Behavior genetic study designs assess genetic and environmental influences in different ways. Adoption studies compare correlations between children and their biological parents or siblings with those between children and their adoptive parents or siblings. To the extent that children resemble biological relatives more than adoptive relatives, this implies genetic influences on behavior. Because there are no adoption studies in this special issue, we provide more detail about the twin design, below.

\section{Twin Design}

Twin studies rely on the presence in nature of two types of twins, monozygotic (MZ) twins, who share $100 \%$ of their genotype because they come from a single, fertilized egg, and dizygotic (DZ) twins, who share on average $50 \%$ of their genetic make-up because they come from two eggs 
fertilized by two different sperm. Although there are variations on the twin design, the basic design includes the comparison of the intra-class correlation between $\mathrm{MZ}$ twins with the intra-class correlation between DZ twins. Basically, a behavior is measured on all children, and if MZ twins are significantly more alike on that measure (have a greater intra-class correlation) than are DZ twins, this implies genetic influence on the behavior (see Plomin et al. 2013 for a more complete explanation).

One important assumption that the twin method requires is the equal environments assumption (EEA). This assumption states that $\mathrm{MZ}$ and $\mathrm{DZ}$ twin environments do not differ significantly in terms of how they affect the behavior under study. For example, parents may dress MZ twins alike more than they do DZ twins, but this has not been shown to affect the behaviors that psychologists are interested in. If children who were dressed more similarly were more likely to engage in delinquent acts in a similar fashion, then the EEA would be violated in studies of delinquency. This becomes a tricky question because genes and environment so frequently are correlated and we have great difficulty extricating them. Genes often drive the increased similarity in the environment. Thus, although MZ twins may share a more similar environment, if this is driven by their greater genetic similarity, it does not appear to violate the EEA (Eaves et al. 2003).

\section{Molecular Genetic Studies}

As DNA analyses have become affordable, researchers have begun attempting to identify specific genes that are related to certain behavioral traits. Because behavior is complex and multi-determined, most behaviors are influenced by a medley of genetic and environmental influences. Narrowing down specific environments that predict behaviors has always been difficult, and it is no different with attempting to identify genes that affect behaviors. Because many different genes influence any given behavior, each specific gene will only account for a very small percent of the variance in the behavior (Risch 2000). This becomes further complicated by the fact that genes and environments are inextricably inter-related, as discussed below. Nonetheless, researchers have been identifying a number of candidate genes that appear to show relations with certain behaviors.

A problem with identifying certain genes is that replication is essential, and frequently studies from different samples do not yield the same results (Tabor et al. 2002). Additionally, large samples are ideal for having sufficient power to detect small, replicable results (Dick et al. 2015; Lohmueller et al. 2003). However, we believe that thoughtful, hypothesis-driven studies are valuable as long as the researchers are cognizant of potential replication problems. Notably, a large number of studies have found that the DRD4 gene, which encodes proteins that respond to the neurotransmitter dopamine in the brain, is related to a number of externalizing types of behaviors, such as novelty seeking, aggression, and hyperactivity (Banaschewski et al. 2010; Farbiash et al. 2014; Ray et al. 2009). Similarly, other genes have been identified repeatedly across different studies, suggesting that they code for neurotransmitter action in the brain that is related to certain behaviors. For example, short alleles of the promotor polymorphism (5HTTLPR) of the 5HTT serotonin transporter gene have been shown to relate to increased aggression in children and adolescents (Beitchman et al. 2006; Davidge et al. 2004) as well as rhesus monkeys (Bennett et al. 2002; Suomi 2006). The muscarinic acetylcholine receptor M2 gene (CHRM2) has been demonstrated in huge samples to be related to alcohol dependence (Luo et al. 2005) and also to generalized externalizing problem behaviors (Dick et al. 2008). Thus, although clearly replication is a problem that must be addressed, there are certainly a number of genes that appear to be strong candidates for further study. This special issue includes several articles that find further support for some of these, specifically with respect to dopamine genes DRD4, DRD2 and DAT1.

To more thoroughly understand causes of behavior, it is essential to examine the extent to which genes as well as environment affect behaviors, and it is useful to attempt to isolate specific genes that may have a (small) impact on behaviors. However, because psychological behaviors are so complex, almost all behaviors of interest will have both genetic and environmental influences. To truly understand how behaviors develop, we must include the study of genes and environment as they act in concert with each other. Theories exist for gene-environment correlation as well as gene-environment interaction, as described briefly below.

\section{Gene-Environment Correlation (rGE)}

There are many situations in which genes and environment are intercorrelated. Plomin et al. (1977) and Scarr and McCartney (1983) hypothesized three types of rGE. Passive rGE occurs when children's genes and their environment come from the same source, their parents. This may be most common in infancy and early childhood, but this can still be operating in adolescence. For instance, teenagers may act aggressively partly as a function of their genotype, but they may also be exposed to an aggressive home environment because their parents are aggressive within the home. Thus, if these adolescents are aggressive, it is difficult to distinguish whether that is because they are genetically prone to aggression or whether they are imitating the aggression they experience at home. The 
second is reactive, or evocative, rGE. This occurs when something about the adolescent that is genetically influenced evokes a certain reaction from the environment, thus causing the adolescent's genes and environment to be correlated. For example, an adolescent may be genetically likely to be very behaviorally inhibited. Other youth may react to her reticence by avoiding her, leading to an environment that is isolated and therefore increases the adolescent's inhibition. Thus, her genes and her environment are correlated and difficult to distinguish etiologically. Third, active rGE occurs when adolescents choose environments based in part on their own genotype. For example, an adolescent who is genetically more likely to behave prosocially may actively choose to engage in experiences that involve helping others and may join groups of youth who are similarly prosocial. This also is called nichepicking. Again, their genes and environments are correlated and it is difficult to determine which are causally related to their current behaviors.

\section{Gene-Environment Interaction $(\mathbf{G} \times \mathbf{E})$}

$\mathrm{G} \times \mathrm{E}$ occurs when there is genetic sensitivity to the environment, resulting in people with different genotypes responding differently in different environments. For example, youth with a certain genotype might respond very aggressively in one environment, but they might not show this aggression in another type of environment. Youth without that genotype might not be aggressive at all, or they might have an opposite response to the two environments. There are several forms that $\mathrm{G} \times \mathrm{E}$ can take. The oldest hypothesis is diathesis-stress (Gottesman 1991), whereby a particular disorder is exhibited if there is genetic risk plus a particular negative environment (as demonstrated in Fig. 1). Without the negative environment, the disorder will lie dormant. More recently, a differential susceptibility hypothesis has been put forward (Ellis et al. 2011). This hypothesis suggests that those with a certain genotype are more susceptible to environmental influence, such that those with the genotype in a positive environment will show particularly positive outcomes, but those in a negative environment will show particularly negative outcomes (see hypothetical example in Fig. 2). The behaviors of those without the genotype will not differ across the different environments. Finally, a third type of $\mathrm{G} \times \mathrm{E}$ is the bioecological interaction (Burt and Klump 2014). If this occurs, then genetic effects on a behavior can be seen in positive environments, where there is freedom for the behavior to be expressed, but those effects are not evident in restricted environments, where all the variance for behavior is accounted for by environmental influences (see hypothetical example in Fig. 3). Several of the articles in this special issue use $\mathrm{G} \times \mathrm{E}$ models across a variety of samples and behaviors.

\section{Behavior Genetics and Parenting Influences in Adolescence}

Parenting behavior has been consistently linked with children's adjustment across childhood and adolescence. In general, parental warmth and support are linked to more optimal adjustment for youth, and parental harshness and negativity are linked to the development of behavioral and emotional problems (Crosnoe and Cavanagh 2010; Demo and Cox 2000; Denham et al. 2000; Fletcher et al. 2004; Park et al. 2005). Family relationships, such as the parentchild relationship, traditionally have been conceptualized as exerting their influence on child and adolescent outcomes via purely environmental mechanisms. Thus, heritable characteristics of the family members and the influence these characteristics may have on the relationship were not traditionally considered. When genetic factors are not taken into account in family studies, this allows for the possible confounding of environmental and genetic effects, and it is unclear precisely how parenting and youth adjustment are linked.

Early and subsequent behavioral genetic investigations have demonstrated genetic effects on a variety of measures of the family environment (Kendler and Baker 2007; Reiss 1995). For example, significant genetic effects have been indicated for parent and adolescent twin ratings of the parent-offspring relationship quality. Riemann et al. (2012) found moderate to strong genetic influences on ratings of parent-offspring relationship quality independent of the informants. Although genetic influences are evident in family relationships, this does not discount the importance of environmental influences. For example, significant shared environmental influences have been indicated in the link between parenting quality and social-emotional and behavioral development spanning infancy to adolescence for attachment (Roismann and Fraley 2008), externalizing behavior (Saudino et al. 2008), and conduct disorder and peer deviance (Kendler et al. 2008). Significant nonshared environment effects also have been indicated in the link between parenting quality and externalizing and internalizing behavior problems (Fagan and Najman 2003; Liang and Eley 2005; Mullineaux et al. 2009).

More recent work focusing on the parent-child relationship has moved beyond demonstrating independent genetic and environmental influences to examine how gene-environment interplay may operate within this context. This body of work provides clear evidence that the parent-child relationship is influenced by genotype- 

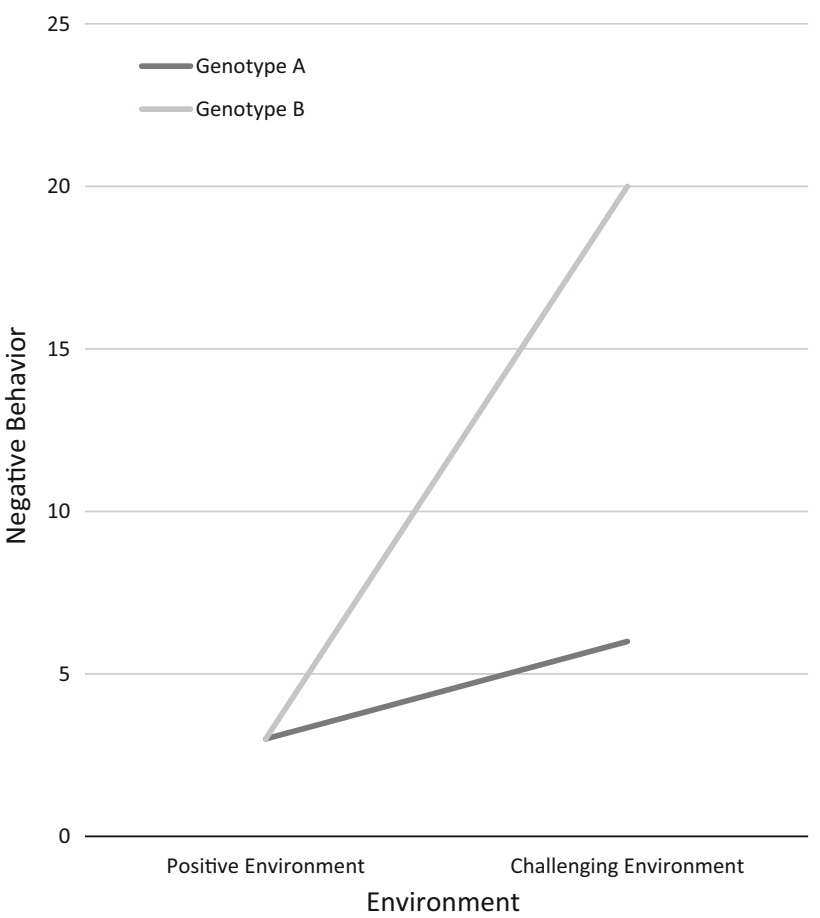

Fig. 1 Hypothetical example of data conforming to the diathesisstress model. With genotype A, there is little increase in negative behavior even in a challenging environment. With genotype $\mathrm{B}$, there is a significant increase in negative behavior in a challenging environment

environment correlations. As discussed above, rGE can involve passive, active, or reactive processes; however, the parenting literature has primarily focused on passive and reactive rGE, as a child cannot select his or her parents. Much of this work has focused on parenting behaviors and further elucidation of the link between parenting and youth adjustment.

From a developmental theory of genetics, it is suggested that passive rGE processes may be primarily evident during infancy and reactive rGE may primarily be evident during childhood and possibly beyond as children begin to spend more time outside the family environment (Scarr and McCartney 1983). Although these rGE processes may change in their degree of impact across development, this does not mean that they are necessarily mutually exclusive. For example, work examining parenting behavior in response to adolescent characteristics indicated that different forms of rGE might be working simultaneously to explain parenting behavior. Neiderhiser et al. (2004) found evidence of both passive rGE and reactive rGE in parenting behavior during adolescence. In this study, passive rGE was indicated for maternal positivity and monitoring whereas reactive rGE was indicated for maternal negativity and control. This suggests that mothers are providing a positive environment for their children as well as genes
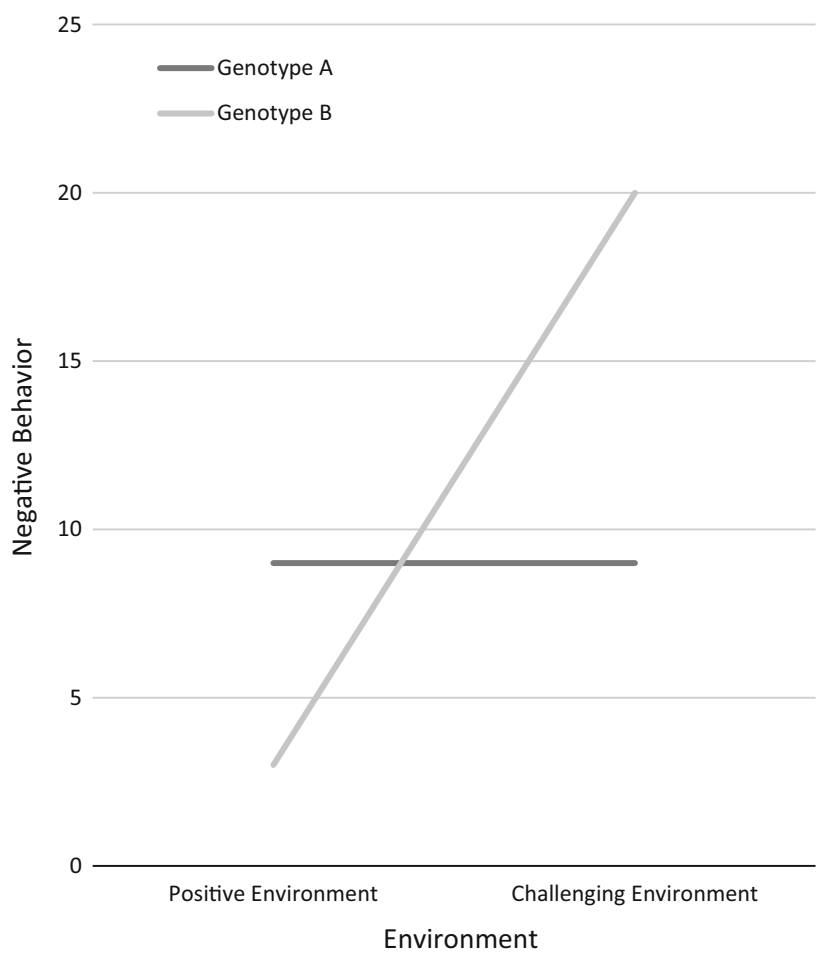

Fig. 2 Hypothetical example of data that fit a differential susceptibility model. Youth with genotype A do not appear to respond to changes in their environment in terms of the outcome measure. However, youth with genotype B have lower scores on the negative behavior in a positive environment and have much higher negative behavior scores in a challenging environment

consistent with this, but they are responding to negativity in their children when they themselves behave negatively or use strict control measures.

Interestingly, mothers and fathers appear to exhibit different patterns of parenting rGE. In a follow-up study, Neiderhiser et al. (2007) found that maternal positivity was due to passive rGE, but paternal positivity was attributed to fathers' perception of child positivity in response to their adolescents' heritable characteristics. Paternal negativity was attributed to both passive and reactive rGE whereas maternal negativity was primarily attributed to reactive rGE. Evidence of reactive rGE for maternal control also has been indicated during middle childhood (Klahr et al. 2013). These findings provide evidence that parenting behavior arises from a complex interaction between genes and environments and that these rGE processes may be acting in tandem to explain aspects of the parent-child relationship.

Gene-environment interplay also has been examined to further understand the link between parenting and child adjustment. The majority of this work has examined the link between parenting behavior and the development of externalizing behavior across childhood and adolescence. 


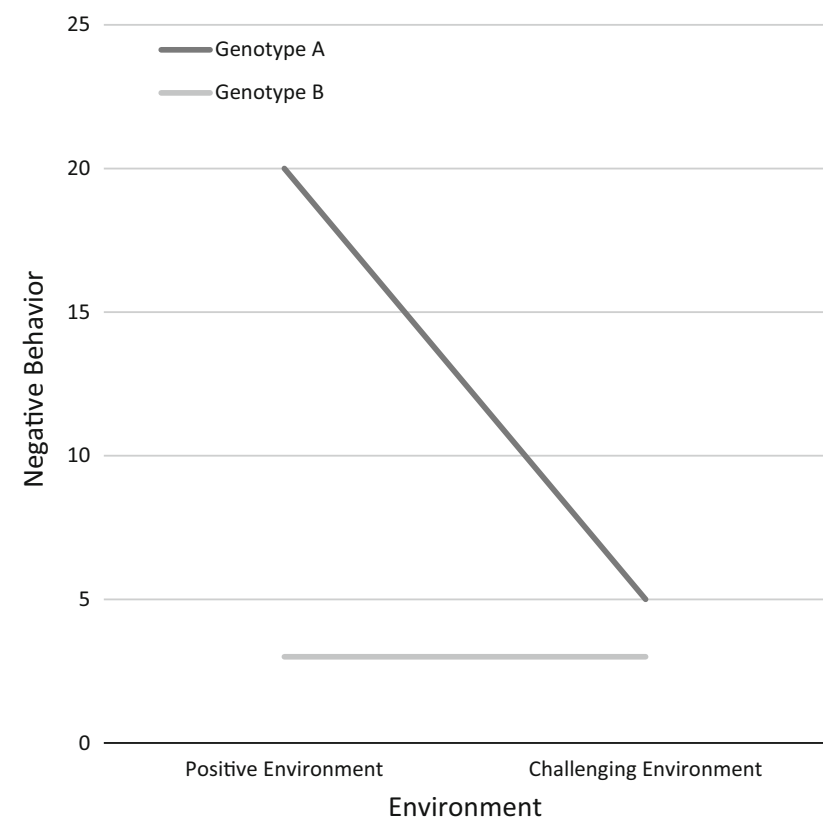

Fig. 3 Hypothetical example of the bioecological model. Youth in the challenging environment do not show genetic differences on the outcome measure because genetic expression is being suppressed. Youth in the positive environment are able to express their genotype more fully. Note that in this example, to be consistent with the other figures, it is a negative thing to be able to express this genotype fully, as it results in more negative behavior

In general, findings from these studies frequently indicate that a significant proportion of the phenotypic correlation between parenting and child adjustment is attributed largely to overlapping genetic effects, with the remaining variance being accounted for by varying degrees of shared and nonshared environmental effects (Burt et al. 2005; Reiss et al. 2000). These findings suggest reactive rGE processes, as the heritable characteristics of a child may evoke more negative parenting behavior, which in turn may further shape the child's behavioral problems.

Marceau et al. (2013) examined passive and reactive rGE for mother and father negativity and adolescent externalizing behavior in two independent samples. Reactive rGE was indicated for both mother and father negativity and adolescent externalizing behavior. Thus, when adolescents exhibited higher rates of externalizing behaviors, parents reported engaging in more conflictual, coercive, and punitive parenting behaviors.

In the relationship between parenting behavior and children's adjustment, differences have been found in the association between maternal and paternal practices and externalizing behaviors in their adolescent children (Formoso et al. 2000; Videon 2005). This pattern was demonstrated in a recent study examining the link between parental criticism and externalizing behavior. The link between maternal criticism and adolescent problem behavior was explained by reactive rGE whereas paternal criticism was not. Paternal criticism did not occur in response to adolescent problem behavior, but rather directly affected it through environmental pathways (Narusyte et al. 2011). However, more recent work has suggested that reactive rGE, although pervasive in adolescence and young adulthood, may dissipate in adulthood. Examination of the link between parent-adolescent relationship problems and externalizing problems across the transition from adolescence (age 18) to young adulthood (25 years of age) indicated that genetic influences on externalizing behavior problems was greatest when more parent-adolescent relationship problems were reported, which is indicative of reactive rGE (Samek et al. 2015). However, there was no evidence of genetic moderation at age 25 years, which indicates that the reactive rGE was no longer present.

Evidence of rGE effects across childhood and adolescence is clear. Interestingly, both passive and reactive rGE processes may serve as underlying mechanisms in the welldocumented association between parenting behavior and child externalizing behavior problems. However, work examining whether these rGE effects persist over development does suggest that for some aspects of the parentchild relationship and offspring behavior problems, it may dissipate in later adulthood. Further research examining the persistence or dissipation of rGE effects is needed to more clearly understand its developmental impact across the lifespan. The next step in uncovering gene-environment interplay is to determine which genes parents (and others) are responding to when reactive rGE effects are present. For example, a recent examination of parental positivity and self-control behavior during early childhood indicated that boys with the 5-HTTLPR long allele predicted higher levels of positivity, which was mediated by the boys' selfcontrol (Pener-Tessler et al. 2013). However, these results must be taken with caution until replicated.

\section{Behavior Genetics and Peer Influences in Adolescence}

Adolescence is a time when peer relationships take on an increasingly vital role in development (Gardner and Steinberg 2005). Although the family is still an important influence on youth behaviors, peers become even more important than family (Roisman et al. 2004). Early research on this topic assumed that peers influenced youth strictly through environmental means, but behavior genetic research on this topic has demonstrated that there are strong genetic influences at work as well. This can be interpreted most easily through $\mathrm{rGE}$ and $\mathrm{G} \times \mathrm{E}$ influences. If reactive rGE is occurring, then youth may evoke certain responses from the peers around them partly as a function of their 
own genotype, thus creating an environment that is correlated with their genotype. If active rGE is occurring, then youth may be engaging in niche-picking, or choosing to place themselves in environments that fit their genotypes. This actually fits well with propositions offered by traditional social learning theorists who posit that youth who are prone to behaving delinquently choose peers who encourage such behavior (Gottfredson and Hirschi 1990). If $\mathrm{G} \times \mathrm{E}$ are occurring, then youth with certain genotypes will respond to various types of peer environments in ways that differ from youth with different genetic make-up. To truly understand the role that peers play in influencing development, it is essential to include these genetic influences in our theories of adolescent development.

One of the primary adolescent behaviors that has been studied from a behavior genetics perspective is deviancy or delinquency. This behavior is particularly interesting because most youth who engage in delinquent behaviors do so with a peer group (Van Lier et al. 2007). Originally, twin studies suggested that delinquency showed no heritability whereas adult criminality showed fairly high heritability (DiLalla and Gottesman 1989), but those findings were based primarily on court report data. Findings from studies since then, many using youth self-report, have been mixed, with some showing fair to quite high heritability for delinquency and others showing no evidence for genetic influence (Tarantino et al. 2014). The most likely scenario is that most youth engage in delinquent behaviors as a normative phase, outgrowing such behaviors when they reach adulthood. However, a subset of youth appear to have genetic underpinnings to these behaviors, and these may be the ones who continue with criminal activity in adulthood (DiLalla and Gottesman 1991; Moffitt 1993). If indeed genetic influences are significant for delinquency, we also must question how those genetic influences interact with the peer environment and how these interactions may change with development.

A genetic correlation between adolescent delinquency and adolescent peers' delinquent behaviors has been demonstrated. In one study, shared genetic influence between these two measures was very high (71-79\% across two assessments) for youth in middle school to high school (Boisvert et al. 2014). This finding supports the likelihood of rGE between adolescent genotype and their delinquent peer affiliation. As noted above, this could occur through passive, reactive, or active means, although passive mechanisms are the least likely. This is an important finding because it demonstrates the importance of considering genetic events even in situations where we know that the environment relates to an outcome behavior, in this case delinquency.

Another longitudinal study involved asking youth at ages 15, 18, and 21 years about their friends' deviant behaviors (Tarantino et al. 2014). Although this study did not include information about the twins' actual behaviors, the researchers did demonstrate that peer behavior shows genetic influence, which means that adolescents' environments are subject to heritable influences. The most likely mechanism is rGE, although it is impossible to distinguish from this study which type of correlation was occurring. It is possible that adolescents who inherit certain personality types or behavioral traits consistent with delinquent behaviors are also exposed by their parents (who gave them those genes) to delinquent types of peers because they are family friends. Thus, deviant parents may share both deviant genotype as well as deviant environments with their children, yielding passive rGE. This mechanism of transmission has not been tested, and future studies should consider it. It is perhaps more likely that adolescents with personality types or behavioral traits consistent with delinquency attract the attention of similar peers, which would be reactive rGE. Finally, it also is likely that these deviant-prone adolescents choose to hang out with similar peers, which would be indicative of active rGE. All of these scenarios would basically act like a snowball effect, with the environment supporting genetic tendencies and genotype strengthening environmental effects.

Tarantino et al. (2014) also noted that genetic effects on peer deviancy increased from age 15-21, with new genetic influences appearing at age 18 but not at 21. This may reflect the increasing independence of adolescents from their families through age 18 , which may asymptote toward the end of adolescence, where nonshared environmental effects begin to be stronger than shared environment, meaning that family influences decrease. They also found similar results for both boys and girls, demonstrating that these results are generalizable to both sexes.

In an examination of $\mathrm{G} \times \mathrm{E}$ for peer aggression, rather than delinquency, Kretschmer et al. (2014) found that 15-year-olds' aggressive behaviors differed based on their own genotype and their exposure to aggressive peers. Specifically, they examined youth with different variants of the brain-derived neurotrophic factor (BDNF) gene, which mediates synaptic plasticity in the brain and spinal cord. This gene is important for programmed cell death and appears to be related to anxiety and depression in stressful situations (Chen et al. 2015). Kretschmer et al. found that adolescents differed in their responses to aggressive peers depending on which form of BDNF they had. Those who were homozygous for the Val allele were somewhat more aggressive than others when none of their peers were aggressive, but they were significantly less aggressive than others in the presence of aggressive peers. The opposite was true for adolescents who were homozygous for the Met allele. The researchers suggest that the mechanism for this may be via stress regulation because the BDNF gene is 
involved in cortisol responses and therefore may be involved in adolescents' responses to the stressor of peer aggression. Similarly to Tarantino et al. (2014), they also found no sex differences.

Thus, it is clear from the behavior genetic literature on aggression and delinquency in adolescence that genes and environment are inter-related. Both play a role, possibly independently and certainly together, in affecting deviant behavior in adolescence. It is particularly interesting that genetic influences are demonstrated for peer affiliation because this provides further evidence (Plomin et al. 1988) that our environments are influenced by our genotypes.

\section{Overview of Special Issue Contributions}

We now briefly comment on the seven empirical studies included in this special issue and their contributions to furthering our current understanding of genetic influences on peer and family relationships across preadolescence to adolescence. Taken together, they provide important information about the roles of genes and environment during this developmental period.

All of the articles in this special issue use genetically informed samples to further examine the genetic and environmental influences on peer and family relationships across preadolescence and adolescence. The article by $\mathrm{Li}$ et al. (2015) examines the moderating effects of family relationships on preadolescent and adolescent adjustment. $\mathrm{Li}$ et al. (2015) found that parent-adolescent relationships high in coercion moderated the genetic risk on deviant peer affiliation. When parents engaged in more coercive parenting behaviors, genetic and nonshared environmental influences on deviant peer association increased. This study highlights the importance of considering the influence of parent-adolescent relationship quality on genetic factors in understanding the variability in adolescent peer affiliation.

The articles by Vitaro et al. (2015) and Connolly et al. (2015) both examine the effects of peer groups on antisocial behaviors and delinquency. Vitaro et al. (2015) examined how peer group acceptance of aggressive and nonaggressive antisocial behavior influenced preadolescents' behavior. Peer acceptance of general antisocial behavior resulted in higher rates of antisocial behavior for all children. However, when peers were not accepting of general antisocial behavior, genetically at-risk children were not dissuaded from engaging in antisocial behavior. Connolly et al. (2015) found that shared and nonshared environmental influences accounted for significant variation in peer pressure to engage in delinquent acts and self-reported delinquency. Interestingly, the covariation between peer pressure and delinquency was explained by environmental effects (shared and nonshared) in preadolescence, but was explained by genetic and nonshared effects during adolescence. These findings highlight the importance of examining how genetic and environmental effects may change across development. Together, those findings indicate that negative peer environments do support children's engagement in antisocial and delinquent behavior. However, those children who are genetically at-risk may not be as sensitive to socialization that discourages these genetically predisposed behaviors.

Four of the articles in this special issue examine $\mathrm{G} \times \mathrm{E}$ mechanisms during preadolescence and adolescence across several different samples. Each of these articles considers the role of dopamine as it interacts with different types of environmental influences. The consistent results across studies add to the reliability of the results, although the methods and actual measures differ. Nonetheless, all of these studies provide evidence for significant $\mathrm{G} \times \mathrm{E}$ using genes that regulate dopamine, increasing confidence that these findings are meaningful and worthy of further pursuit. Three of the articles examine DRD4 genotype in interactions with peer environments, and all three find significant predictions of externalizing behavior problems. One of these studies also examined the DAT1 dopamine genotype and found similar results, and another one found similar results also for youth prosocial behaviors. A fourth paper assessed DRD2 genotype and its interaction with the parenting environment, finding support for a significant effect on child depression. Overall, these papers provide support for the important role of dopamine in interaction with the peer and family environment in affecting behaviors of preadolescent and adolescent children.

Specifically, three articles in this issue address youth externalizing behaviors in the context of $\mathrm{G} \times \mathrm{E}$. Buil et al. (2015) found that children with a 7-repeat (7R) allele for the DRD4 gene showed differential susceptibility to their environment. These children were tested annually from ages 9 to 12 years, and their conduct problem scores differed depending on whether they were rated high or low on social preference scores by their school peers. 7R children who were rated high on positive social preference showed the lowest levels of conduct problems, whereas 7R children who were rated high on negative social preference showed the most conduct problems. This differential responding to the peer environment did not occur for children without the 7-repeat allele. Similarly, DiLalla et al. (2015) examined the DRD4 genotype in children and pre-adolescents aged 6-10 years of age within the context of presence or absence of peer victimization in the peer environment. They also found evidence of differential susceptibility. 7R children who were exposed to a great amount of verbal victimization were most likely to self-report high levels of externalizing problem behaviors, but $7 \mathrm{R}$ children who reported no exposure to verbal victimization had the lowest levels of externalizing behaviors. Children without the $7 \mathrm{R}$ 
allele showed no differences in externalizing as a function of peer victimization experiences. Janssens et al. (2015) showed differential susceptibility effects for DAT1, although they did not find it for DRD4. In a slightly older sample of adolescents, they found that youth with the risk allele for DAT1 who also experienced peer rejection were rated as having more externalizing problem behaviors, but those who did not experience peer rejection had low levels of externalizing. This same pattern did not hold for DRD4. Interestingly, in both the Buil et al. and Janssens et al. studies, $\mathrm{G} \times \mathrm{E}$ effects were not shown for positive behaviors, either for positive environment (peer acceptance; Janssens et al.) or positive outcomes (prosocial behaviors; Buil et al.). Thus, overall, a $\mathrm{G} \times \mathrm{E}$ differential susceptibility model appears to fit data well when examining dopamine genotypes and negative peer environments as they impact externalizing behavior during the pre-adolescent and adolescent periods.

Finally, Zhang et al. (2015) examined $\mathrm{G} \times \mathrm{E}$ and internalizing problems. Rather than considering the peer environment, they assessed maternal positive and negative parenting as a possible environmental moderator. Their longitudinal sample of Chinese adolescents was genotyped for DRD2. As with the DRD4 studies, they also found evidence of differential susceptibility. They found that for the younger two assessments (approximately ages 11 and 12 years), youth with the risk TaqIA A1 allele showed high levels of depression if they experienced high negative parenting, but they showed lower levels of depression when they did not experience negative parenting. Youth with the A2A2 genotype did not show any change in depression as a function of negative parenting. This $\mathrm{G} \times \mathrm{E}$ effect was not significant at the oldest age of assessment. Thus, across different cultures and ages, evidence has been presented in this special issue for the validity of a $\mathrm{G} \times \mathrm{E}$ differential susceptibility model. Overall, it appears to provide a good fit to the data when examining dopamine genotypes and negative environments, for both externalizing and internalizing behavior problems.

\section{Conclusion}

The importance of considering the influences of genetic and environmental factors, as well as gene-environment interplay, on peer and family relationships is clear based on the extant literature reviewed. The articles in this special issue further add to our growing understanding of how genes and environments work together through peer and family relationships to create the variety of developmental outcomes observed across pre-adolescence and adolescence. However, as is evident from this review, genetically informed research with respect to the role that peer and family relationships play in pre-adolescent and adolescent development is still relatively new when compared to the depth of research already conducted from an environment-focused behavioral perspective. Nonetheless, the results from these quantitative and candidate gene studies do indicate that genetic factors not only play a role in shaping various aspects of adolescent development, but also may moderate how these peer and familial experiences affect future adjustment.

Much more research is required before we can gain a comprehensive understanding of how genes and peer and family relationships work in tandem across the transition from childhood to adolescence. For example, longitudinal research is required to explore potential developmental changes not only in genetic and environmental influences more broadly, but also for rGE processes in relationship to peer and family relations and youth adjustment. Several of the articles in this special issue examine $\mathrm{G} \times \mathrm{E}$ mechanisms by examining theoretically-driven genetic markers; however, few genetic markers for social behaviors or traits have withstood replication and these findings should be taken with caution. Thus, although this special issue makes important inroads into disentangling the gene-environment relationship in adolescence, much more innovative and replication work is necessary.

This special issue makes an important contribution to research on adolescent development by highlighting some of the ground-breaking work done in this area and by presenting new $\mathrm{rGE}$ and $\mathrm{G} \times \mathrm{E}$ data. Our focus on family and peer environments as they relate to genotype brings these important adolescent environments to the fore for behavior genetic research. Some of these articles provide additional support that genes associated with dopamine regulation are important genetic markers for social behaviors. Although much remains to be elucidated in our understanding of these gene-environment processes, these genetically informed studies provide another glimpse into the intricate ways that genes and environments work in concert to shape adolescent adjustment through family and peer relationships.

Author contributions L.D. conceived the special issue. L.D. and P.M. equally contributed to the draft of the introduction manuscript. Both authors read and approved the final manuscript.

Conflict of interest The authors declare that they have no conflict of interest.

\section{References}

Bakermans-Kranenburg, M. J., \& van Ijzendoorn, M. H. (2007). Genetic-environment interaction of the dopamine D4 receptor (DRD4) and observed maternal insensitivity predicting externalizing behavior in preschoolers. Developmental Psychobiology, 48, 1160-1173. 
Banaschewski, T., Becker, K., Scherag, S., Franke, B., \& Coghill, D. (2010). Molecular genetics of attention-deficit/hyperactivity disorder: An overview. European Child and Adolescent Psychiatry, 19, 237-257. doi:10.1007/s00787-010-0090-z.

Bank, L., Burraston, B., \& Snyder, J. (2004). Sibling conflict and ineffective parenting as predictors of adolescent boys' antisocial behavior and peer difficulties: Additive and interactional effects. Journal of Research on Adolescence, 14, 99-125.

Beitchman, J. H., Baldassarra, L., Mik, H., De Luca, L., King, N., Bender, D., et al. (2006). Serotonin transporter polymorphisms and persistent, pervasive, childhood aggression. American Journal of Psychiatry, 163, 1103-1105.

Bennett, A. J., Lesch, K. P., Heils, A., Long, J. C., Lorenz, J. G., Shoaf, S. E., et al. (2002). Early experience and serotonin transporter gene variation interact to influence primate CNS function. Molecular Psychiatry, 7, 118-122.

Boisvert, D., Boutwell, B. B., Vaske, J., \& Newsome, J. (2014). Genetic and environmental overlap between delinquent peer association and delinquency in adolescence. Criminal Justice and Behavior, 41, 58-74. doi:10.1177/0093854813495022.

Boivin, M., Vitaro, F., \& Poulin, F. (2005). Peer relationships and the development of aggressive behavior in early childhood. In R. E. Tremblay, W. W. Hartup, \& J. Archer (Eds.), Developmental origins of aggression (pp. 376-397). New York, NY: Guilford Press.

Buil, J. M., Koot, H. M., Olthof, T., Nelson, K. A., \& van Lier, P. A. C. (2015). DRD4 genotype and the developmental link of peer social preference with conduct problems and prosocial behavior across ages 9-12 years. Journal of Youth and Adolescence. doi:10.1007/s10964-015-0289-x.

Bukowski, W. M., Brengden, M., \& Vitaro, F. (2006). Peer relations. In J. E. Grusex \& P. D. Hastings (Eds.), Handbook of socialization (pp. 355-381). New York, NY: Guilford Press.

Burt, S. A., \& Klump, K. L. (2014). Parent-child conflict as an etiological moderator of childhood conduct problems: An example of a 'bioecological' gene-environment interaction. Psychological Medicine, 44, 1065-1076. doi:10.1017/S003329 1713001190.

Burt, S. A., McGue, M., Krueger, R. F., \& Iacono, W. G. (2005). How are parent-child conflict and childhood externalizing symptoms related over time? Results from a genetically informed crosslagged study. Development and Psychopathology, 17, 99-136.

Chen, L., Pan, H., Tuan, T. A., Teh, A. L., MacIsaac, J. L., et al. (2015). Brain-derived neurotrophic factor (BDNF) Val66Met polymorphism influences the association of the methylome with maternal anxiety and neonatal brain volumes. Development and Psychopathology, 27, 137-150. doi:10.1017/S095457941 4001357.

Connolly, E. J., Schwartz, J. A., Nedelec, J. L., Beaver, K. M., \& Barnes, J. C. (2015). Different slopes for different folks: Genetic influences on growth in delinquent peer association and delinquency during adolescence. Journal of Youth and Adolescence. doi:10.1007/s10964-015-0299-8.

Crosnoe, R., \& Cavanagh, S. E. (2010). Families with children and adolescents: A review, critique, and future agenda. Journal of Marriage and Family, 72, 594-611.

Davidge, K. M., Atkinson, L., Douglas, L., Lee, V., Shapiro, S., Kennedy, J. L., \& Beitchman, J. H. (2004). Association of the serotonin transporter and 5HT1D[beta] receptor genes with extreme, persistent and pervasive aggressive behaviour in children. Psychiatric Genetics, 14, 143-146.

Demo, D. H., \& Cox, M. J. (2000). Families with young children: A review of research in the 1990's's. Journal of Marriage and Family, 62, 876-895.

Denham, S. A., Workman, E., Cole, P. M., Weissbrod, C., Kendziora, K. T., \& Zahn-Waxler, C. (2000). Prediction of externalizing behavior problems from early to middle childhood: The role of parental socialization and emotion expression. Development and Psychopathology, 12, 23-45.

Dick, D., Agrawal, A., Keller, M. C., Adkins, A., Aliev, F., Monroe, S., et al. (2015). Candidate gene-environment interaction research: Reflections and recommendations. Perspectives on Psychological Science, 10, 37-59.

Dick, D. M., Aliev, F., Wang, J. C., Grucza, R. A., Schuckit, M., Kuperman, S., et al. (2008). Using dimensional models of externalizing psychopathology to aid in gene identification. Archives of General Psychiatry, 65(3), 310-318.

DiLalla, L. F., Bersted, K., \& Gheyara, S. J. (2015). Peer victimization and DRD4 genotype influence problem behaviors in young children. Journal of Youth and Adolescence. doi:10.1007/ s10964-015-0282-4.

DiLalla, L. F., \& DiLalla, D. L. (1995). What is "heritability" and what is it not? Midwestern Educational Researcher, 8, 36-37.

DiLalla, L. F., \& Gottesman, I. I. (1989). Heterogeneity of causes for delinquency and criminality: Lifespan perspectives. Development and Psychopathology, 1, 339-349.

DiLalla, L. F., \& Gottesman, I. I. (1991). Biological and genetic contributors to violence-Widom's untold tale. Psychological Bulletin, 109(1), 125-129.

DiLalla, L. F., Mullineaux, P. Y., \& Biebl, S. J. W. (2012). Socialemotional development through a behavior genetics lens: Infancy through preschool. In J. Benson (Ed.), Advances in child development and behavior (Vol. 42, pp. 153-196). London: Elsevier Pub.

Eaves, L., Foley, D., \& Silberg, J. (2003). Has the 'equal environments' assumption been tested in twin studies? Twin Research, 6(6), 486-489. doi:10.1375/136905203322686473.

Ellis, B. J., Boyce, W. T., Belsky, J., Bakermans-Kranenburg, M. J., \& van IJzendorn, M. H. (2011). Differential susceptibility to the environment: An evolutionary-neurodevelopmental theory. Development and Psychopathology, 23, 7-28.

Fagan, A. A., \& Najman, J. M. (2003). Associations between early childhood aggression and internalizing behavior for sibling pairs. Journal of the American Academy of Child and Adolescent Psychiatry, 42, 1093-1100.

Farbiash, T., Berger, A., Atzaba-Poria, N., \& Auerbach, J. G. (2014). Prediction of preschool aggression from DRD4 risk, parental ADHD symptoms, and home chaos. Journal of Abnormal Child Psychology, 42(3), 489-499. doi:10.1007/s10802-013-9791-3.

Fletcher, A. C., Steinberg, L., \& Williams-Wheeler, M. (2004). Parental influences on adolescent problem behavior: Revisiting Stattin and Kerr. Child Development, 75, 457-465.

Formoso, D., Gonzales, N. A., \& Aiken, L. S. (2000). Family conflict and children's internalizing and externalizing behavior: Protective factors. American Journal of Community Psychology, 28, 175-199.

Gardner, M., \& Steinberg, L. (2005). Peer influence on risk taking, risk preference, and risky decision making in adolescence and adulthood: An experimental study. Developmental Psychology, 41, 625-635. doi:10.1037/0012-1649.41.4.625.

Gass, K., Jenkins, J., \& Dunn, J. (2007). Are sibling relationships protective? A longitudinal study. Journal of Child Psychology and Psychiatry, 48, 167-175.

Gottesman, I. I. (1991). Schizophrenia genesis: The origins of madness. New York: Freeman.

Gottfredson, M., \& Hirschi, T. (1990). A general theory of crime. Palo Alto, CA: Stanford University Press.

Haworth, C. M. A., Wright, M. J., Luciano, M., Martin, N. G., de Geus, E. J. C., van Beijsterveldt, C. E. M., \& Plomin, R. (2010). The heritability of general cognitive ability increases linearly from childhood to young adulthood. Molecular Psychiatry, 15, 1112-1120. 
Janssens, A., Van Den Noortgate, W., Goossens, L., Verschueren, K., Colpin, H., De Laet, S., et al. (2015). Externalizing problem behavior in adolescence: Dopaminergic genes in interaction with peer acceptance and rejection. Journal of Youth and Adolescence. doi:10.1007/s10964-015-0304-2.

Kaczynski, K. J., Lindahl, K. M., Malik, N. M., \& Laurenceau, J. (2006). Marital conflict, maternal and parental parenting, and child adjustment: A test of mediation and moderation. Journal of Family Psychology, 20, 199-208.

Kendler, K. S., \& Baker, J. H. (2007). Genetic influences on measures of the environment: A systematic review. Psychological Medicine, 37, 615-626.

Kendler, K. S., Jacobson, K., Myer, J. M., \& Eaves, L. J. (2008). A genetically informative developmental study of the relationship between conduct disorder and peer deviance in males. Psychological Medicine, 38, 1001-1011.

Kim-Cohen, J., Caspi, A., Taylor, A., Willams, B., Newcombe, R., Craig, I. W., \& Moffitt, T. E. (2006). MAOA, maltreatment, and gene-environment interaction predicting children's mental health: New evidence and a meta-analysis. Molecular Psychiatry, 11, 903-913.

Klahr, A. M., Thomas, K. M., Hopwood, C. J., Klump, K. L., \& Burt, S. A. (2013). Evocative gene-environment correlation in the mother-child relationship: A twin study of interpersonal processes. Development and Psychopathology, 25, 105-118.

Kretschmer, T., Vitaro, F., \& Barker, E. D. (2014). The association between peer and own aggression is moderated by the BDNF Val-Met polymorphism. Journal of Research on Adolescence, 24(1), 177-185. doi:10.1111/jora.12050.

Li, M., Chen, J., Li, X., \& Deater-Deckard, K. (2015). Moderation of harsh parenting on genetic and environmental contributions to child and adolescent deviant peer affiliation: A longitudinal twin study. Journal of Youth and Adolescence. doi:10.1007/s10964015-0288-y.

Liang, H., \& Eley, T. C. (2005). A monozygotic twin differences study of nonshared environmental influence on adolescent depressive symptoms. Child Development, 76, 1247-1260.

Lohmueller, K. E., Pearce, C. L., Pike, M., Lander, E. S., \& Hirschhorn, J. N. (2003). Meta-analysis of genetic association studies supports a contribution of common variants to susceptibility to common disease. Nature Genetics, 33(2), 177-182.

Luo, X., Kranzler, H. R., Zuo, L., Wang, S., Blumberg, H. P., \& Gelernter, J. (2005). CHRM2 gene predisposes to alcohol dependence, drug dependence, and affective disorders: Results from an extended case-control structured association study. Human Molecular Genetics, 14(16), 2421-2432.

Marceau, K., Horwitz, B. N., Narusyte, J., Ganiban, J. M., Spotts, E. L., Reiss, D., \& Neiderhiser, J. M. (2013). Gene-environment correlation underlying the association between parental negativity and adolescent externalizing problems. Child Development, 84, 2031-2046.

McCartney, K., Harris, M. J., \& Bernieri, F. (1990). Growing up and growing apart: A developmental meta-analysis of twin studies. Psychological Bulletin, 107, 226-237.

McGue, M., Bouchard, T. J, Jr, Iacono, W. G., \& Lykken, D. T. (1993). Behavioral genetics of cognitive ability: A lifespan perspective. In R. Plomin \& G. E. McClearn (Eds.), Nature, nurture, and psychology (pp. 59-76). Washington, DC: American Psychological Association.

Moffitt, T. E. (1993). "Life-course-persistent" and "adolescencelimited" antisocial behavior: A developmental taxonomy. Psychological Review, 100, 674-701.

Mullineaux, P. Y., Deater-Deckard, K., Petrill, S. A., \& Thompson, L. A. (2009). Parenting and child behaviour problems: A longitudinal analysis of nonshared environment. Infant and Child Development, 18, 133-148.
Narusyte, J., Neiderhiser, J. M., Andershed, A. K., D’Onofrio, B. M., Reiss, D., Spotts, E., et al. (2011). Parental criticism and externalizing behavior problems in adolescents: The role of environment and genotype-environment correlation. Journal of Abnormal Psychology, 120, 365-376.

Neiderhiser, J. M., Reiss, D., Lichtenstein, P., Spotts, E. L., \& Ganiban, J. (2007). Father-adolescent relationships and the role of genotype-environment correlation. Journal of Family Psychology, 21, 560-571.

Neiderhiser, J. M., Reiss, D., Pederson, N. L., Lichtenstein, P., Spotts, E. L., Hansson, K., et al. (2004). Genetic and environmental influences on mothering of adolescents: A comparison of two samples. Developmental Psychology, 40, 335-351.

Park, J. H., Essex, M. J., Zahn-Waxler, C., Armstrong, J. M., Klein, M. H., \& Goldsmith, H. H. (2005). Relational and overt aggression in middle childhood: Early child and family risk factors. Early Education and Development, 16, 233-257.

Pener-Tessler, R., Avinun, R., Uzefovsky, F., Edelman, S., Ebstein, R. P., \& Knafo, A. (2013). Boys'serotonin transporter genotype affects maternal behavior through self-control: A case of evocative gene-environment correlation. Development and Psychopathology, 25, 151-162.

Plomin, R. (1986). Development, genetics, and psychology. Hillsdale, NJ: Erlbaum.

Plomin, R., DeFries, J. C., Knopik, V. S., \& Neiderhiser, J. M. (2013). Behavioral genetics (6th ed.). New York, NY: Worth Publishers.

Plomin, R., DeFries, J. C., \& Loehlin, J. C. (1977). Genotypeenvironment interaction and correlation in the analysis of human behavior. Psychological Bulletin, 84, 309-322.

Plomin, R., McClearn, G. E., Pedersen, N. L., Nesselroade, J. R., \& Bergeman, C. S. (1988). Genetic influence on childhood family environment perceived retrospectively from the last half of the life span. Developmental Psychology, 24(5), 738-745.

Ray, L. A., Bryan, A., MacKillop, J., McGeary, J., Hesterberg, K., \& Hutchison, K. E. (2009). The dopamine D4 receptor (4) gene exon III polymorphism, problematic alcohol use and novelty seeking: Direct and mediated genetic effects. Addiction Biology, 14(2), 238-244. doi:10.1111/j.1369-1600.2008.00120.x.

Reiss, D. (1995). Genetic influence on family systems: Implications for development. Journal of Marriage and the Family, 57, 543-560.

Reiss, D., Neiderhiser, J. M., Hetherington, E., \& Plomin, R. (2000). The relationship code: Deciphering genetic and social influences on adolescent development. Cambridge, MA: Harvard University Press.

Rettew, D. C., \& McKee, L. (2005). Temperament and its role in developmental psychopathology. Harvard Review of Psychiatry, 13(1), 14-27.

Richmond, M. K., Stocker, C. M., \& Rienks, S. L. (2005). Longitudinal associations between sibling relationship quality, parental differential treatment, and children's adjustment. Journal of Family Psychology, 19, 550-559.

Riemann, R., Kandler, C., \& Bleidorn, W. (2012). Behavioral genetic analyses of parent twin relationship quality. Personality and Individual Differences, 53, 398-404.

Risch, N. J. (2000). Searching for genetic determinants in the new millennium. Nature, 405, 847-856.

Roisman, G. I., Masten, A. S., Coatsworth, J. D., \& Tellegen, A. (2004). Salient and emerging developmental tasks in the transition to adulthood. Child Development, 75, 123-133. doi:10.1111/j.1467-8624.2004.00658.x.

Roismann, G. I., \& Fraley, R. C. (2008). A behavior-genetic study of parenting quality, infant attachment security, and their covariation in a nationally representative sample. Developmental Psychology, 44, 831-839.

Samek, D. R., Hicks, B. M., Keyse, M. A., Bailey, J., McGue, M., \& Iacono, W. G. (2015). Gene-environment interplay between 
parent-child relationship problems and externalizing disorders in adolescence and young adulthood. Psychological Medicine, 45, 333-344.

Saudino, K. J. (2005). Behavioral genetics and child temperament. Journal of Developmental and Behavioral Pediatrics, 26, 214-223.

Saudino, K. J., Carter, A. S., Purper-Ouakil, D., \& Gorwood, P. (2008). The etiology of behavioral problems and competencies in very young twins. Journal of Abnormal Psychology, 117, $48-62$.

Scarr, S., \& McCartney, K. (1983). How people make their own environments: A theory of genotype $\rightarrow$ environment effects. Child Development, 54, 424-435.

Suomi, S. J. (2006). Risk, resilience, and gene $\times$ environment interactions in Rhesus monkeys. Annals of the New York Academy of Sciences, 1094, 52-62.

Tabor, H. K., Risch, N. J., \& Myers, R. M. (2002). Candidate-gene approaches for studying complex genetic traits: Practical considerations. Nature Reviews Genetics, 3(5), 391-397.

Tarantino, N., Tully, E. C., Garcia, S. E., South, S., Iacono, W. G., \& McGue, M. (2014). Genetic and environmental influences on affiliation with deviant peers during adolescence and early adulthood. Developmental Psychology, 50(3), 663-673.

Thapar, A., Harold, G., Rice, F., Langley, K., \& O'Donovan, M. (2007). The contribution of gene-environment interaction and psychopathology. Development and Psychopathology, 19, 989-1004.

Tucker, C. J., \& Updegraff, K. (2009). The relative contributions of parents and siblings to child and adolescent development. New Directions for Child and Adolescent Development, 126, 13-28.

Tucker-Drob, E. M., Briley, D. A., \& Harden, P. (2013). Genetic and environmental influences on cognition across development and context. Current Directions in Psychological Science, 22, 349-355.

Tucker-Drob, E. M., Rhemtulla, M., Harden, K. P., Turkheimer, E., \& Fask, D. (2011). Emergence of a gene $\times$ socioeconomic status interaction on infant mental ability between 10 months and 2 years. Psychological Science, 22, 125-133.

Turkheimer, E. (2000). Three laws of behavior genetics and what they mean. Current Directions in Psychological Science, 9, 160-164.

Turkheimer, E., Haley, A., Waldron, M., D’Onofrio, B., \& Gottesman, I. I. (2003). Socioeconomic status modifies heritability of IQ in young children. Psychological Science, 14, 623-628.

Van Lier, P., Wanner, B., \& Vitaro, F. (2007). Onset of antisocial behavior, affiliation with deviant friends, and childhood maladjustment: A test of the childhood and adolescent-onset models. Development and Psychopathology, 19, 167-185.
Videon, T. M. (2005). Parent-child relations and children's psychological well-being: Do dads matter? Journal of Family Issues, 26, 55-78.

Vitaro, F., Brendgen, M., Girard, A., Boivin, M., Dionne, G., \& Tremblay, R. E. (2015). The expression of genetic risk for aggressive and non-aggressive antisocial behavior is moderated by peer group norms. Journal of Youth and Adolescence. doi:10. 1007/s10964-015-0296-y.

Wachs, T. D. (1983). The use and abuse of environment in behaviorgenetic research. Child Development, 54, 396-407.

Williams, S. T., Conger, K. J., \& Blozis, S. A. (2007). The development of interpersonal aggression during adolescence: The importance of parents, siblings, and family economics. Child Development, 78, 1526-1542.

Williams, L. R., Degnan, K. A., Perez-Edgar, K. E., Henderson, H. A., Rubin, K. H., Pine, D. S., et al. (2009). Impact of behavioral inhibition and parenting style on internalizing and externalizing problems from early childhood through adolescence. Journal of Abnormal Child Psychology, 37, 1063-1075.

Zhang, W., Cao, Y., Wang, M., Ji, L., Chen, L., \& Deater-Deckard, K. (2015). The dopamine D2 receptor polymorphism (DRD2 TaqIA) interacts with maternal parenting in predicting early adolescent depressive symptoms: Evidence of different susceptibility and age differences. Journal of Youth and Adolescence. doi:10.1007/s10964-015-0297-x.

Paula Y. Mullineaux, Ph.D is an Associate Professor at Hamline University in the Department of Psychology. She received her doctorate degree in 2006 from Southern Illinois University-Carbondale. Dr. Mullineaux's research interests include behavior genetics of social emotional development and adjustment during middle childhood, with an emphasis on temperament. Gene-environment interplay related to the link between parent-child and sibling relationship quality and childhood adjustment.

Lisabeth Fisher DiLalla, Ph.D is a Full Professor at Southern Illinois University School of Medicine in Family and Community Medicine. She received her doctorate degree in 1987 from the University of Virginia. Dr. DiLalla's research interests include behavior genetics and early child social development, with an emphasis on aggressive and prosocial development. Gene-environment inter-relations as they affect children's aggressive and victimization behaviors are of particular interest. 